\title{
THE REAL OPTIONS APPROACH \\ TO VALUATION: CHALLENGES AND OPPORTUNITIES*
}

\section{EduARdo SchWARTz ${ }^{* *}$}

This paper provides an overview of the real options approach to valuation mainly from the point of view of the author who has worked in this area for over 30 years. After a general introduction to the subject, numerical procedures to value real options are discussed. Recent developments in the valuation of complex American options has allowed progress in the solution of many interesting real option problems. Two applications of the real options approach are discussed in more detail: the valuation of natural resource investments and the valuation of research and development investments.

JEL classification: G12

Keywords: Real options

\section{INTRODUCTION}

The real options approach is an extension of financial options theory to options on real/non-financial assets. Options are contingent decisions that provide the opportunity to make a decision after uncertainty unfolds. Uncertainty and the agent's ability to respond to it (flexibility) are the source of value of an option. Whenever possible, real options valuations are aligned with financial market valuations.

Most investments are subject to options valuation. There are four main types of options associated with investment projects-the option to expand, to postpone, to abandon, and to temporarily suspend an investment. For example, the option to expand a project is valuable when a firm may want to invest in a negative net present value (NPV) project if it provides the firm the possibility of developing a new project. Consider the valuation of a mine of which, at current commodity prices, only half is economically feasible for development. This investment will provide the option to develop the remainder of the mine when and if market prices change. In this case, the option to expand is valuable and must be considered when quantifying the value of the mine. On

* This lecture was delivered at the 2013 Finance UC Conference in Santiago, Chile. Hay Jin Kim provided valuable assistance.

** California Chair in Real Estate and Land Economics Professor of Finance, Anderson School of Management, University of California, Los Angeles. Email: eduardo.schwartz@anderson.ucla.edu. 
the other hand, even with a positive NPV project, the option to delay the investment is valuable as it gives the firm the opportunity to wait until more market information is available. Furthermore, the option to abandon a project is important and valuable in research and development $(\mathrm{R} \& \mathrm{D})$ investments as it provides the flexibility to abandon a project in the presence of negative outcomes. In contrast to the traditional approach that uses expected cash-flows to value investment projects, the real option approach takes into account the entire distribution of cash-flows, allowing the firm to react/respond during the course of the investment. Finally, the option to temporarily suspend production is valuable whenever a firm has the opportunity to open and temporarily close a facility. For instance, when a commodity price is low, the firm can choose to close its facility and re-open it later when prices are higher.

Thus, flexibility can be an important component of value for many investment projects and the option-pricing framework provides a powerful tool for analyzing such flexibility. Furthermore, the real options approach to valuation is currently being applied in practice and extended in several directions. In particular, this method has been broadened to take into account competitive interactions and their impact on option exercise strategies.

The remainder of this paper is organized as follows. Section 2 compares the two main approaches to value investment projects. Section 3 briefly describes three procedures used to solve option valuation problems. Section 4 presents two particular applications of the real option approach in investment projects. Finally, Section 5 concludes.

\section{Two VAluation approaches}

Even in the absence of real options there are two main approaches to value investment projects. The traditional valuation technique, known as discounted cash-flows (DCF) or net present value (NPV), requires forecasts. It uses a single expected value of future cashflows. A simplified version of the traditional approach is:

$$
N P V=C_{0}+\sum_{t=1}^{N} \frac{C_{t}}{(1+k)^{t}}
$$

where $C_{t}$ is the expected cash flow in period $t$ and $k$ is the risk-adjusted discount rate. By defining cash flows as the profits obtained by the investment project, Equation (1) can be rewritten as: 


$$
N P V=C_{0}+\sum_{t=1}^{N} \frac{q_{t} S_{t}-\text { Cost }_{t}}{(1+k)^{t}}
$$

where $q_{t}$ is the quantity produced and $S_{t}$ is the spot price, assumed to be the only source of uncertainty in this simplified version.

There are two main drawbacks to the traditional approach that makes it inappropriate for valuing projects in many practical situations. First, DCF assumes that future firm decisions are fixed at the outset and ignores the flexibility in decision making during the course of the investment project. Second, when there are options (e.g., exit option) involved in the investment project, it is difficult to find an appropriate discount rate $\mathrm{k}$ to calculate the NPV in Equation (1).

Alternatively, the risk-neutral $(\mathrm{RN})$ valuation or certainty-equivalent (CE) approach can effectively capture the flexibility embedded in real options valuation. In the $\mathrm{CE}$ approach, the adjustment for risk is in the probability distribution of cash flows instead of the discount rate. The NPV of a project is then calculated by discounting the certainty equivalent cash flows $C E Q_{t}$ by the risk-free rate:

$$
r_{f}: N P V=C_{0}+\sum_{t=1}^{N} \frac{C E Q_{t}}{\left(1+r_{f}\right)^{t}}=C_{0}+\sum_{t=1}^{N} \frac{q_{t} F_{t}-\text { Cost }_{t}}{\left(1+r_{f}\right)^{t}}
$$

As can be observed in Equation (3), in order to calculate the certainty equivalent cash flows, futures prices $F_{t}$ are used instead of the spot prices $S_{t}$. Futures prices are the expected future spot prices under the risk-neutral distribution.

Cox and Ross (1976), Harrison and Kreps (1979), and Harrison and Pliska (1981) show that the absence of arbitrage implies the existence of a probability distribution, such that securities are priced at their discounted (at the risk-free rate) expected cash flows under these riskneutral or risk-adjusted probabilities. Moreover, these probabilities are unique if markets are complete-all risks can be hedged. If, on the other hand, markets are not complete, their probabilities are not unique, but any of them can be used for pricing. ${ }^{1}$

1. The risk-neutral valuation approach can be generalized to include stochastic discount rates: $V_{0}=E^{Q}\left[e^{\int_{0}^{T}-r_{f}(t) d t} X_{T}\right]$ 
There are three cases to consider in real option risk-neutral valuation. The first case is when the risk-neutral distribution is known, as in the Black-Scholes framework; unfortunately, the only pure example of this case in the real world are gold mines. In such case, the futures prices are $F_{o, T}=S_{o}\left(1+r_{f}\right)^{T}$.

The second case is when the risk-neutral distribution is unknown but can be obtained from futures prices or other traded assets (e.g., copper mines and oil deposits). In Section 4 this topic will be explored further.

The last case is when the risk-neutral distribution is unknown and futures prices do not exist. In this case the risk-neutral distribution can be obtained by using an equilibrium model, such as the CAPM. This is the most common case in R\&D projects, Internet companies, and information technology where no futures prices exist.

Thus, using the risk-neutral framework to value investment projects allows for use of all information contained in futures prices when these prices exist, to take into account all flexibilities/options the projects may have and use the powerful analytical tools that have been developed in contingent claims analysis.

\section{Solution PRocedures to Option VALUATION PROBLEMS}

There are three main solution methods for solving option valuation problems: the dynamic programming approach, partial differential equations, and the simulation approach. The first approach uses dynamic programming techniques to lay out possible future outcomes and folds back the value of the optimal future strategy using riskneutral distributions. The binomial method is a dynamic programming approach widely employed to value simple options. It can also be used to price American-type options. However, this solution method becomes inadequate when there are multiple factors affecting the value of the option or when there are path dependencies.

The second method directly solves the partial differential equations (PDE) that result from most option pricing problems. This approach leads to closed-form solutions in very few cases, such as the BlackScholes equation for European call options. In most option valuation problems the PDE has to be solved numerically. This is a very flexible method, and it is appropriate for valuing American options. Finding a solution however becomes extremely complicated when there are 
more than three state variables; thus, PDE is an inadequate method for solving the more complex real option problems. Furthermore, this method is technically sophisticated as it needs to approximate boundary conditions.

In general option pricing problems can also be solved by simulation. The simulation approach is very powerful; however, it is forward-looking whereas the optimal exercise of an American option has dynamic programming features.

Longstaff and Schwartz (2001) developed a simulation approach to valuing American options. An American option gives its holder the right to exercise at multiple points in time (finite number) before its maturity date. At each exercise point, the holder optimally compares the immediate exercise value with the value of continuation. As standard theory implies that the value of continuation can be expressed as the conditional expected value of discounted future cash flows, the basic idea behind the simulation approach is that the conditional expected value of continuation can be estimated from the cross-sectional information from the simulation by least-squares. The conditional expectation function is estimated by regressing discounted ex-post realized cash flows from continuation on functions of the current (or past) values of the state variables. The fitted value from this cross-sectional regression is shown to be an efficient estimator of the conditional expectation function. Thus, by estimating the conditional expectation function for each exercise date in each of the possible simulated paths, an optimal stopping rule for the option and hence its current value can be accurately estimated.

Among all three solution methods, the most useful tool for solving real options valuation problems is the simulation approach. It is easily applied to multi-factor models and directly applicable to pathdependent problems. Furthermore, it allows the state variables to follow general stochastic processes. It is intuitive, transparent, flexible, easily implemented, and computationally efficient.

\section{Applications of the real options approach}

Since Longstaff and Schwartz (2001) developed the simulation approach, complex real option valuation problems have been analyzed in numerous areas. Two particular applications of the real option approach will be discussed in this section: natural resource investments and pharmaceutical R\&D investments. 


\subsection{Natural resource investments}

Commodity-linked bonds were increasingly issued in the late 1970s. For instance, the Mexican government issued bonds backed by oil in 1979. A year later, in 1980, Sunshine Mining Company issued bonds backed by silver in the United States. In addition, gold-backed bonds have been around for a long time. Schwartz (1982) attempts to value commodity assets. He proposes a model, based on the Black-Scholes option pricing framework extended by Merton (1973) and Cox and Ross (1976), to deal with the problem of accurately valuing commodity-linked bonds. These bonds' payouts (coupon and/or principal) are directly linked to the market price of the underlying commodity (such as oil, copper, or gold), the interest rate, and the value of the firm.

The earlier work on natural resource investment valuation assumed that commodity prices follow a simple stochastic process similar to that of stock prices. This simplistic assumption is found to be appropriate for gold but inadequate for other types of commodities: Supply and demand adjustments induce mean reversion in commodity prices. On the supply side, an increase in the commodity price will induce highcost producers to enter the market which, in turn, will decrease the market price; once the price is low, those high-cost producers will exit the market to avoid negative profits, increasing the market price once again. On the demand side, when the market price is high, consumers will substitute the commodity and demand for it will fall, resulting in a decrease in the commodity price.

Brennan and Schwartz (1985) acknowledge that the evaluation of mining and other natural resource projects is difficult due to uncertainty in commodity prices; they propose that mine and oil deposits can be interpreted and valued as complex options on the underlying commodities. This is one of the first papers on real options valuation. The valuation model takes explicitly into account managerial control over the output rate and the possibility of abandoning the project if output prices decrease substantially. The approach relies on constructing a self-financing portfolio of riskless bonds and futures contracts whose cash flows replicate those of the investment project to be valued. The main assumptions underlying this replication are "that the convenience yield on the output commodity can be written as a function of the output price alone, and that the interest rate is nonstochastic." 
Subsequent works on commodity asset valuation have focused on making more realistic assumptions about the stochastic processes followed by commodity prices. For instance, Cortazar and Schwartz (2003) develop a three-factor model of the term structure of oil futures prices that can be estimated from available futures price data. The procedure is flexible and can take into account the dynamics of futures prices. The true stochastic process of spot prices is modeled as:

$$
\begin{aligned}
& d S=(v-y) S d t+\sigma_{1} S d z_{1} \\
& d y=-\kappa y d t+\sigma_{2} d z_{2} \\
& d v=a(\bar{v}-v) d t+\sigma_{3} d z_{3}
\end{aligned}
$$

where $v$ can be interpreted as the long-term drift of the process and $y$ can be interpreted as the convenience yield. Both $v$ and $y$ are mean reverting processes, which in turn induce some mean reversion in $S$. However, in order to value options, a risk-neutral process is needed. For instance, assuming that the market prices of risk $\left(\lambda_{1}, \lambda_{2}\right.$, and $\left.\lambda_{3}\right)$ are constants, the risk-adjusted processes are

$$
\begin{aligned}
& S=\left(v-y-\lambda_{1}\right) S d t+\sigma_{1} S d z_{1} \\
& d y=\left(-\kappa y-\lambda_{2}\right) d t+\sigma_{2} d z_{2} \\
& d v=\left(a(\bar{v}-v)-\lambda_{3}\right) d t+\sigma_{3} d z_{3}
\end{aligned}
$$

Futures prices can be analytically derived from these equations. The joint processes can then be estimated by a Kalman filter. Using daily prices of all futures contracts traded on the New York Mercantile Exchange (NYMEX) between 1991 and 2001, the estimation results indicate that the model fits the data extremely well.

Some challenges facing all commodity price models are that assumptions about the functional forms of market prices of risks are needed and that we can have confidence in the model's fit only for the period for which we have futures data (typically not more than six years into the future). One of the main challenges of the three-factor model is dealing with longer maturities where no futures prices exist: Should we accept the model predictions for maturities where there are no futures prices? Should we assume that futures prices are constant or that they increase at a fixed rate? What discount rate should we use for longer maturities? 
More recently, Trolle and Schwartz (2009) note that once options data are included in the valuation of commodities (in addition to futures price data), it is critical to understand the dynamics of volatility in commodity markets for pricing, hedging, and risk management of commodity options and real options. While volatility in commodity markets is stochastic, it is not clear the extent to which volatility is spanned by the factors that affect futures prices. Schwartz and Trolle analyze this issue in the crude-oil market and develop a tractable model for pricing commodity derivatives in the presence of unspanned stochastic volatility. The model is then estimated on NYMEX crude-oil derivatives using "an extensive panel data set of 45,517 futures prices and 33,104 option prices, spanning 4082 business days." First, the covariance matrix of the futures returns are factor-analyzed retaining the first three principal components (PCs). Then, the straddle returns or changes in implied volatilities which are used as proxies for changes in actual volatility are regressed on PCs and PCs squared (to take into account possible non-linearities):

$$
\begin{aligned}
r_{t}^{s t r a d, i}= & \beta_{0}^{i}+\beta_{1}^{i} P C_{t}^{f u t, 1}+\beta_{2}^{i} P C_{t}^{f u t, 2}+\beta_{3}^{i} P C_{t}^{f u t, 3} \\
& +\beta_{4}^{i}\left(P C_{t}^{f u t, 1}\right)^{2}+\beta_{5}^{i}\left(P C_{t}^{f u t, 2}\right)^{2}+\beta_{6}^{i}\left(P C_{t}^{f u t, 3}\right)^{2}+\epsilon_{t}^{i}
\end{aligned}
$$

The resulting $R^{2}$ for the regresions are typically low, between $0 \%$ and $21 \%$. Thus, the factors that explain futures prices cannot explain changes in volatility.

Next, in order to check the existence of systematic factors affecting volatility, the covariance matrix of the residuals from these regressions are factor-analyzed. The results indicate that the first two PCs explain over $80 \%$ of the variation in the residuals.

Based on these results, Trolle and Schwartz (2009) develop models with one and two volatility factors, in addition to the factors affecting commodity prices. These were the first models estimated using also options data, in addition to futures price data.

Schwartz and Trolle (2010) use this model to price expropriation risk in a natural resource project. Their approach focuses on some of the important economic trade-offs that arise from a government holding an "option" to expropriate an oil field, abstracting from the various operational options that are typically embedded in natural resource investments. While the main benefit from exercising the expropriation option is that the government receives all the profits 
rather than a fraction through taxes, the expropriation costs are that a private firm may produce oil more efficiently, that the government may have to pay compensation to the firm, and that the government may face "reputational" costs. Given these variables, exercise of the expropriation option by the government is optimally determined. Spot prices, futures prices, and volatilities are described by the dynamics proposed in Trolle and Schwartz (2009). Furthermore, the expropriation option is modeled as an American-style option. At every point in time, the government must compare the value of immediate exercise with the conditional expected value (under the risk-neutral measure) of continuation. The optimal exercise time for each simulated path can then be used to value the expropriation option.

The results indicate that for a given contractual arrangement, the value of the expropriation option increases with the spot price, the slope of the futures curve, and the volatility of the spot (futures) price. On the other hand, for a given set of state variables, the value of the expropriation option decreases with the tax rate and various expropriation costs. Furthermore, the increase in the field's value to the government due to the expropriation option is found to be always smaller than the decrease in the field's value to the firms due to the "deadweight losses" associated with the expropriation process, i.e., production inefficiency and reputational costs.

\subsection{R\&D investments}

The main focus of real options valuation in R\&D investment projects has been on the pharmaceutical industry. However, the pharmaceutical R\&D framework can easily be applied to other research-intensive industries.

The pharmaceutical industry has become a research-oriented sector that makes a major contribution to health care. The success of the industry in generating a stream of new drugs with important therapeutic benefits has created an intense public policy debate over issues such as the financing of research, the prices charged for its products, and the socially optimal degree of patent protection. There is a tradeoff between promoting innovative efforts and securing competitive market outcomes. While expected monopoly profits from drug sales during the life of the patent compensate the innovator for the risky investment, the onset of competition after patent expiration limits the deadweight losses to society that arise from monopoly pricing under 
the patent. Moreover, regulation has had important effects on the cost of innovation in the pharmaceutical industry.

The analysis of R\&D projects in the pharmaceutical industry must take into account some of its unique characteristics. First, the development of a new drug takes a long time; the average is between 10 and 12 years. Second, there is uncertainty about the costs of development and the time to completion. Although the average time to completion is 12 years, the development of a new drug could take 20 years, by which time the patent may expire and the project will therefore be abandoned. Third, there is also a high probability of failure for either technical or economic reasons; for example, $80 \%$ of projects that start clinical trials are later abandoned. Technical reasons include catastrophic events, while economic reasons comprise the high cost of production and the inefficacy of the drugs. Fourth, new drugs require approval by the U.S. Food and Drug Administration (FDA). Finally, once the drug has been approved, there is uncertainty about the level and duration of future cash flows as the time to completion and the length of the patent are also uncertain. As a result of the particular procedure followed by the pharmaceutical researchers and the high $\operatorname{costs}^{2}$ involved in the development stages, an abandonment option is clearly valuable in the pharmaceutical industry and must be considered in the valuation method.

Schwartz (2004) proposes a methodology to quantify the value of a single R\&D project that is patent-protected. Equivalently, the approach aims to determine the price of the patent. Taking into consideration all the unique features of the pharmaceutical industry described above, Schwartz treats the patent-protected R\&D project as a complex option on the variables underlying the value of the project. There are two variables that are taken into consideration: expected costs to completion and anticipated cash flows. By allowing these two variables to follow stochastic processes through time, uncertainty is introduced into the analysis. The expected cost to completion is assumed to follow:

$$
d K=-I d t+\sigma(I K)^{\frac{1}{2}} d z
$$

2. In the United States alone, annual expenditures on prescription drugs were more than US\$300 billion in 2010. For instance, Pfizer Inc., the largest pharmaceutical company in the world, invested over US\$108 billion in R\&D from 1997 to 2011, successfully developing 14 new drugs. In the same period, Amgen Inc. spent over US $\$ 33$ billion on R\&D, with an average investment of $\$ 3.6$ billion per successful drug. 
As can be seen in Equation (7), the cost to completion, $K$, decreases with investments $I$ and is affected by a random shock, such that the volatility of the cost process can be expressed as:

$$
\operatorname{Var}(\tilde{K})=\frac{\sigma^{2} K^{2}}{2-\sigma^{2}}
$$

Concurrently, the cash flows follow a geometric Brownian motion (which may be correlated with the cost-process):

$$
d C=\alpha C d t+\phi C d w
$$

and the associated risk-adjusted process used for valuation is:

$$
d C=(\alpha-\eta) C d t+\phi C d w=\alpha^{*} C d t+\phi C d w .
$$

Due to the absence of futures prices, the risk-adjusted process for the cash-flows (i.e., $\eta$ ) is obtained using the returns of traded pharmaceutical companies.

In this model, the value of the project once investment has been completed will depend on the cash flows and on time: $V(C, t)$. An analytical solution can be found by solving the PDE:

$$
\frac{1}{2} \phi^{2} C^{2} V_{C C}+\alpha^{*} C V_{C}+V_{t}-r V+C=0
$$

setting the following boundary condition:

$$
V(C, T)=M \bullet C .
$$

Condition (12) implies that the value of the project at expiration date $T$ of the patent is a multiple or fraction $M$ of the cash-flows. Thus,

$$
\begin{aligned}
V(C, t)= & \frac{C}{r-\alpha^{*}}\left[1-\exp \left(-\left(r-\alpha^{*}\right)(T-t)\right)\right] \\
& +M C \exp \left(-\left(r-\alpha^{*}\right)(T-t)\right) .
\end{aligned}
$$


Based on Equation (13), the stochastic process for the (true) return on the project once investment is completed can be calculated:

$$
\frac{d V}{V}=(r+\eta) d t+\phi d w
$$

and finally, the market price of risk $(\eta)$ can be obtained using the prices of the traded pharmaceutical companies.

The value of the investment project before the investment has been completed also depends on the expected cost of completion, $F(C, K, t)$. In this case no analytical solution exists for the PDE since the time at completion is uncertain:

$$
\begin{gathered}
\max _{I}\left[\frac{1}{2} \phi^{2} C^{2} F_{C C}+\frac{1}{2} \sigma^{2}(I K) F_{K K}+\phi \sigma \rho C(I K)^{\frac{1}{2}} F_{C K}\right. \\
\left.+\alpha^{*} C F_{C}-I F_{K}+F_{t}-(r+\lambda) F-I\right]=0
\end{gathered}
$$

subject to the boundary condition at completion of investment: $F(C, 0, \tau)=V(C, \tau)$ where $\tau$ is a random variable representing the time of project completion. Nevertheless, this problem can be solved through simulation. By approximating the value of the investment project as an American option, the optimal investment and abandonment strategies are determined, i.e., the project will be abandoned when cash flows are too low and/or expected costs to completion are too high.

Miltersen and Schwartz (2004) analyze pharmaceutical R\&D investments projects with competitive interactions among research firms. This work concentrates on the competitive interaction and its effect on the valuation and optimal investment strategies. Thus, the real options valuation technique is extended to incorporate game-theoretical concepts. Under this framework, two firms invest in $\mathrm{R} \& \mathrm{D}$ for different drugs, both targeted to cure the same disease. If both firms are successful, there are duopoly profits in the marketing phase. Clearly, future expected profits can affect managerial decisions in the development phase, which in turn affect the outcome in the marketing phase. The implementation of this extended real options framework show that competition in $\mathrm{R} \& \mathrm{D}$ 
brings about higher production at lower prices, higher probability of success, and shorter average development time. These benefits are, however, offset by higher total development costs and lower values for $R \& D$ investment projects.

Hsu and Schwartz (2008) adapt the pharmaceutical model of R\&D valuation to incorporate the design of optimal research incentives to examine the problem of pharmaceutical underinvestment in vaccines to treat diseases such as malaria, tuberculosis, and subtypes of HIV common in Africa. These diseases kill more than 5 million people each year, with almost all of these deaths occuring in the developing regions of the world. Nonetheless, there is a lack of private pharmaceutical investment devoted to researching a cure for these diseases. The lack of pharmaceutical investment can be seen as a small market problem: people in developing countries cannot afford to pay for these drugs. Fortunately, certain international organizations and private foundations (e.g., the World Health Organization and the Gates Foundation) are willing to provide funding. However, "there is no consensus on how to administer the sponsorship effectively." There are currently two main types of subsidy programs (see Kremer 2001, 2002) to encourage pharmaceutical innovation: push subsidy and pull subsidy. Push programs subsidize the cost of R\&D projects by providing full discretionary research grants or through sponsor co-payments. In contrast, pull programs subsidize the revenue of $R \& D$ projects through fixed-price purchase commitments, variable price purchase commitments, tax incentives, and/or extended patent protection. Clearly, the firm's price and quantity strategy could depend on the incentive program in place and the monopoly power of the firm.

Hsu and Schwartz quantitatively examine the different incentive programs using the real option valuation framework and by explicitly modelling the quality (or efficacy) of the $R \& D$ output. The quality of the drug is a key determinant of revenue as it affects demand; moreover, quality directly affects the exercise of the abandonment option. Using this framework, this paper seeks to answer five critical questions: What is the required level of monetary incentive to induce the firm to undertake the $R \& D$ to develop the vaccine? What are the expected price, quantity supplied and efficacy of the developed vaccine? What is the probability that a viable vaccine will be developed? What is the consumer surplus generated? What is the expected cost per individual successfully vaccinated? 


\section{CONCLUDiNG REMARKS}

This paper provides an overview of the real options approach to valuation mainly from the point of view of the author who has worked in this area for over 30 years. General development of the valuation of complex American options has allowed progress in the solution of many interesting real option problems. Two applications of the real options approach are discussed in more detail: the valuation of natural resource investments and the valuation of research and development investments.

In addition to dicussing the many opportunities provided by the real options approach to valuation, the paper also mentions some of the challenges that the approach presents. These challenges are the subject of continuing research by the author and other scholars. 


\section{REFERENCES}

Brennan, M. and E.S. Schwartz (1985), "Evaluating natural resource investments," The Journal of Business 58(2): 135-57.

Cortazar, G. and E.S. Schwartz (2003), "Implementing a stochastic model for oil futures prices," Energy Economics 25(3): 215-38.

Hsu, J. and E.S. Schwartz (2008), "A model of R\&D valuation and the design of research incentives," Insurance: Mathematics and Economics 43(3): 350-67.

Longstaff, F. and E.S. Schwartz (2001), "Valuing American options by simulation: A simple least-squares approach," The Review of Financial Studies 14(1): $113-47$.

Miltersen, K. and E.S. Schwartz (2004), "R\&D investments with competitive interactions," NBER Working Paper No. 10,258.

Moon, M. and E.S. Schwartz (2000), "Evaluation of research and development invesments," in M.J. Brennan and L. Trigeorgis, eds., Innovation, infrastructure and strategic options. Oxford: Oxford University Press.

Trolle A.B. and E.S. Schwartz (2009) (2009), "Unspanned stochastic volatility and the pricing of commodity derivatives," Review of Financial Studies 22(11): 4423-61.

Schwartz, E.S. (1982), "The pricing of commodity-linked bonds," The Journal of Finance 37(1): 525-39.

Schwartz, E.S. (2004), "Patents and R\&D as real options," Economic Notes 33(1): 23-54.

Schwartz, E.S. (2013), "The real options approach to valuation: Challenges and opportunities," presentation at Finance UC 4th International Conference, Pontificia Universidad Católica de Chile.

Schwartz, E.S. and A.B. Trolle (2010), "Pricing expropriation risk in natural resource contracts - A real options approach," in W. Hogan and F. Sturzenegger, eds., The natural resources trap: Private investment without public commitment. Cambridge, Mass.: MIT Press. 
